\title{
Contrasting metabolic effects of continuous and pulsatile growth hormone administration in young adults with Type 1 (insulin-dependent) diabetes mellitus
}

\author{
B. R. Pal, P. E. Phillips, D. R. Matthews and D. B. Dunger \\ Department of Paediatrics, John Radcliffe Hospital, Headington, Oxford and Diabetes Research Laboratories, Oxford, UK
}

\begin{abstract}
Summary. Plasma growth hormone profiles in adolescents with Type 1 (insulin-dependent) diabetes mellitus are characterized by both increases in pulse amplitude and higher baseline concentrations. To determine which of these abnormalities adversely affect metabolic control, we studied six young adults overnight on three occasions. On each night somatostatin $\left(50-100 \mu \mathrm{g} \cdot \mathrm{m}^{2-1} \cdot \mathrm{h}^{-1}\right)$ and glucagon ( $1 \mathrm{ng}$. $\mathrm{kg}^{-1} \cdot \mathrm{min}^{-1}$ ) were infused continuously and $18 \mathrm{mU} / \mathrm{kg}$ of growth hormone was given as either: three discrete pulses of $6 \mathrm{mU} \cdot \mathrm{kg}^{-1} \cdot \mathrm{h}^{-1}$ at 180 -min intervals or a 12 -h infusion $\left(1.5 \mathrm{mU} \cdot \mathrm{kg}^{-1} \cdot \mathrm{h}^{-1}\right)$ or buffer solution only on a control night. Euglycaemia was maintained by an insulin-varying clamp. Blood samples were taken every $15 \mathrm{~min}$ for glucose and growth hormone and every hour for intermediate metabolites and non-esterified fatty acids. Comparable normoglycaemic conditions were achieved on all three nights. Growth hormone levels achieved (mean \pm SEM) on study nights were: $32.8 \pm 2.2 \mathrm{mU} / 1$ (peak level during growth hormone pulses); $9.8 \pm 0.8 \mathrm{mU} / 1$ (continuous growth hormone) and $1.1 \pm 0.3 \mathrm{mU} / \mathrm{l}$ (control level). Pulsatile growth hormone administration led to an increase in insulin requirements (mean \pm SEM: $0.17 \pm 0.03$ vs control $0.09 \pm 0.01 \mathrm{mU} \cdot \mathrm{kg}^{-1}$. $\left.\min ^{-1}, p<0.05\right)$ whereas insulin requirements following con-
\end{abstract}

tinuous growth hormone administration were unchanged. Cross-correlation confirmed an increase in insulin requirements occurring $135 \mathrm{~min}$ after a growth hormone pulse $(r=0.21, p<0.001)$. Growth hormone administration (continuous and pulsatile) led to a significant increase in B-hydroxybutyrate levels compared to the control night: $0.21 \pm 0.01 \mathrm{mmol} / \mathrm{l} \quad$ (mean $\pm \mathrm{SEM}$ ), $0.29 \pm 0.01 \mathrm{mmol} / \mathrm{l}$, $0.08 \pm 0.01 \mathrm{mmol} / /(p<0.001)$ during the night with pulsatile growth hormone, continuous growth hormone and control respectively. Mean plasma non-esterified fatty acids were also increased following growth hormone administration: $0.94 \pm 0.04 \mathrm{mmol} / \mathrm{l} \quad$ (mean $\pm \mathrm{SEM}$ ), $1.09 \pm 0.07 \mathrm{mmol} / \mathrm{l}$, $0.61 \pm 0.05 \mathrm{mmol} / 1(p<0.003)$, during the night with pulsatile growth hormone, continuous growth hormone and control respectively. It appears that the pulsatile and baseline growth hormone signals have contrasting metabolic effects in young adults with Type 1 diabetes mellitus.

Key words: Growth hormone, Type 1 (insulin-dependent) diabetes mellitus, pulsatile and continuous growth hormone, insulin requirements, ketones, B-hydroxybutyrate, nonesterified fatty acids.
Increased spontaneous growth hormone $(\mathrm{GH})$ secretion in patients with Type 1 (insulin-dependent) diabetes mellitus is well documented [1-5]. Elevated GH levels cause metabolic decompensation [6] and are implicated both in the pathogenesis of microangiopathic complications $[7,8]$ and in the dawn phenomenon secondary to elevated nocturnal surges of GH [9-12]. We have recently demonstrated a direct relationship between nocturnal $\mathrm{GH}$ and the dawn increase of insulin requirements which was reversed by $\mathrm{GH}$ suppression with the anticholinergic drug, pirenzepine [13].

In normal subjects GH secretion is pulsatile. During adolescence and in young adults, GH is secreted mostly at night. The dominant pulse periodicity of $\mathrm{GH}$ is $180 \mathrm{~min}$ and concentrations tend to return to a low baseline for part of the night [14]. GH secretion is also pulsatile in Type 1 diabetes but profiles are characterized by increased maximal GH amplitude $[5,15]$ and by elevated baseline (non-pulsatile component) concentrations [5, 16]. Deconvolution of GH profiles suggests that the dominant pulse periodicity may also be reduced in Type 1 diabetes [17].

Whereas GH pulsatility has been shown to be important in the generation of insulin-like growth factor I in experimental animals $[18,19]$, the metabolic effects of pulsatile vs continuous $\mathrm{GH}$ administration have been studied less often. Perriello et al. [20] recently reported that nocturnal pulses of GH led to the decreased insulin sensitivity 
of the dawn phenomenon. However, that study did not clearly elucidate whether other reported effects of $\mathrm{GH}$ on ketogenesis and lipolysis were more evident after continuous or pulsatile $\mathrm{GH}$ release.

We have undertaken overnight studies in young adults with Type 1 diabetes where the effects of continuous or pulsatile $\mathrm{GH}$ administration on ketogenesis, lipolysis, and insulin requirements were compared with a control night during which endogenous $\mathrm{GH}$ secretion was suppressed with somatostatin.

\section{Subjects, materials and methods}

The subjects were six young adults (two female, four male, median age: 19 years (range 14-26 years) with Type 1 diabetes. Median duration of diabetes was 10 years (range 6-18 years). Their diabetes was controlled with insulin (median $0.68 \mathrm{U} \cdot \mathrm{kg}^{-1} \cdot$ day $^{-1}$, range 0.45 $0.95 \mathrm{U} \cdot \mathrm{kg}^{-1} \cdot \mathrm{day}^{-1}$ ) given two to four times daily. They were taking no other medication. The median $\mathrm{HbA}_{1}$ level was $8.8 \%$ and was measured close to the date of study (range $6-12.5 \%$; reference range $3.8-6.0 \%$ ). The median weight was $66.6 \mathrm{~kg}$ (range $52-80.75 \mathrm{~kg}$ ), median surface area $1.78 \mathrm{~m}^{2}$ (range $1.48-2.05 \mathrm{~m}^{2}$ ) and they were nonobese (median BMI $23.6 \mathrm{~kg} / \mathrm{m}^{2}$, range $21.9-26.9 \mathrm{~kg} / \mathrm{m}^{2}$ ). All had normal renal and thyroid function. The studies were approved by the Central Oxford Research Ethics Committee and were carried out at the John Radcliffe Hospital, Oxford.

\section{Study design}

Each subject was admitted on three separate nights (19.0008.00 hours). Four out of the six subjects participated on all three nights; one for the pulsatile GH study and control; and one for 12-h continuous GH study and control. The study was double-blind to both operator and patient and the sequence of these studies was varied at random.

Nocturnal GH plasma levels found in Type 1 diabetes [5] were reproduced in study subjects by an estimate of $\mathrm{GH}$ secretory dose using deconvolution $[17,21]$ of an overnight GH plasma profile (previously obtained from an adolescent with diabetes) to achieve similar physiological plasma levels in the subjects studied. A total dose of $18 \mathrm{mU} / \mathrm{kg} \mathrm{r}-\mathrm{hGH}$ was given as either a $12-\mathrm{h}$ continuous intravenous infusion ( $1.5 \mathrm{mU} \cdot \mathrm{kg}^{-1} \cdot \mathrm{h}^{-1}$ given between $20.00-08.00$ hours) to achieve a raised baseline level; or three separate 1 -h pulses $\left(6 \mathrm{mU} \cdot \mathrm{kg}^{-1} \cdot \mathrm{h}^{-1}\right.$ at $22.00-23.00$ hours, $01.00-02.00$ hours, $04.00-$ 05.00 hours) to reproduce the pattern of nocturnal pulses of GH. On a control night no $\mathrm{GH}$ was given. On all study nights endogenous $\mathrm{GH}$ secretion was suppressed by a somatostatin infusion and glucagon was infused. Euglycaemic conditions were maintained using a variable rate insulin infusion. The rate of the insulin infusion was calculated by a microcomputer programme [22]. The target blood glucose concentration entered into the programme for the clamp studies was $5.0 \mathrm{mmol} / \mathrm{l}$. During the clamp, the mean insulin infusion rate required for the attainment of a steady blood glucose concentration within the euglycaemic range was calculated.

\section{Procedures}

An identical protocol was performed on each night: withdrawal of exogenous insulin, the evening meal and cannulation were as previously described [13]. Subjects were admitted at 16.30 hours on the study day and had their evening meal before 18.00 hours. A double lumen catheter was inserted into a main vein at the wrist of one arm and a second cannula into the antecubital vein of the same arm.

The cannula (Viggo, 22 gauge) inserted into the antecubital vein and attached to a $y$-connector was used for the infusion of insulin, somatostatin, glucagon and GH. The insulin infusion $(0.1 \mathrm{U} / \mathrm{ml})$ was made by adding $5 \mathrm{U}$ of soluble insulin (Actrapid; Novo, Copen- hagen, Denmark) and $2 \mathrm{ml}$ of subject's blood (to prevent adsorption) to $48 \mathrm{ml} 0.9 \% \mathrm{NaCl}$. The syringe was changed three times during the night and new insulin was used on each occasion. The insulin was infused using a Treonic IP3 Syringe pump (Vickers Medical, Basingstoke, UK).

The somatostatin infusate $(30 \mu \mathrm{g} / \mathrm{ml})$ was made by adding $1.5 \mathrm{mg}$ of somatostatin 1-14 (Stilamin, Serono, S.p.A, Rome, Italy) to $0.9 \% \mathrm{NaCl}$ and was infused at a rate of $50-100 \mu \mathrm{g} \cdot \mathrm{m}^{2-1} \cdot \mathrm{h}^{-1}$ between $19.00-08.00$ hours by a similar Vickers syringe pump. The solution was changed after $6 \mathrm{~h}$.

A glucagon infusion $(1 \mu \mathrm{g} / \mathrm{ml})$ was prepared by adding $0.5 \mathrm{mg}$ of glucagon (Novo Industri, Bagsvaerd, Denmark) to $0.9 \% \mathrm{NaCl}$ and this was infused through a Vickers syringe pump at a rate of $1 \mathrm{ng}$. $\mathrm{kg}^{-1} \cdot \mathrm{min}^{-1}$ between $19.00-08.00$ hours.

The $\mathrm{GH}$ solution $(80 \mathrm{mU} / \mathrm{ml})$ was prepared by adding $4 \mathrm{IU}$ r-hGH (Genotropin, Kabi, Stockholm, Sweden) to $50 \mathrm{ml}$ of phosphate buffer solution (aminoacetic acid (glycine) $24 \mathrm{mg} / \mathrm{ml}$; sodium dehydrogen phosphate $0.65 \mathrm{mg} / \mathrm{ml}$; monosodium dihydrogen phosphate $0.3 \mathrm{mg} / \mathrm{ml}$ ). During the control night, buffer only was infused. The GH/buffer or buffer only was provided to the operator in $50 \mathrm{ml}$ syringes labelled as solution $\mathrm{A}$ and solution $\mathrm{B}$. Solution $\mathrm{A}$ was infused at a steady rate of $0.02 \mathrm{ml} \cdot \mathrm{kg}^{-1} \cdot \mathrm{h}^{-1}(20.00-08.00$ hours $)$ using a Vickers syringe pump. Solution B was infused at $0.08 \mathrm{ml} \cdot \mathrm{kg}^{-1} \cdot \mathrm{h}^{-1}$ at three separate hourly periods, using a modified Vickers pump attached in series circuit to a multi-function digital timer (setting accuracy: $\pm 0.5 \%$ of set time; repeat accuracy: $\pm 0.3 \%$ of set time) which was programmed for a time setting of $60 \mathrm{~min}$ on and $120 \mathrm{~min}$ off to control the infusion rate. The clock was set to start at 20.00 hours in "off" phase.

The intravenous cannula inserted into the hand was used for sampling using a continuous blood withdrawal system via a WatsonMarlow 101 U peristaltic pump (Watson-Marlow Ltd, Marlow, UK), The forearm was maintained in a heated box throughout the night to arterialise the venous blood [23]. The blood was prevented from clotting by use of a double-lumen cannula and continuous heparinization [22].

The blood was collected in 15-min aliquots in lithium-heparin tubes for later GH assay but the first two or three drops of blood from each tube were collected in fluoride tubes for immediate blood glucose assay. Hourly samples were also collected in lithium-heparin tubes for plasma free insulin, metabolites and non-esterified fatty acids (NEFA) assays.

When all study nights were completed, the code for random assignment was opened and analysis of data was carried out.

\section{Samples and assays}

Whole blood glucose concentration was determined by a Yellow Springs Instruments analyser (Clandon Scientific Ltd, Hants, UK).

Samples for $\mathrm{GH}$ assay were spun, separated and the plasma was frozen and stored at $-20^{\circ} \mathrm{C}$ until assay. Plasma GH concentrations were measured by immunoradiometric assay (Netria, St Bartholomew's Hospital, London, UK) using an international reference standard 80/505 and all the samples from each individual overnight profile were analysed in the same batch. The inter-assay coefficients of variation (CV) at $\mathrm{GH}$ concentrations of $3.5,15.2$ and $77.4 \mathrm{mU} / \mathrm{I}$ were $9.4 \%, 7.7 \%$ and $10.5 \%$ respectively and the intra-assay $\mathrm{CV}$ at $\mathrm{GH}$ concentrations of $2.9,14.3$ and $69.4 \mathrm{mU} / \mathrm{l}$ were $8.0 \%, 2.0 \%$ and $3.4 \%$ respectively.

For measurement of plasma free insulin, $1.0 \mathrm{ml}$ whole blood was added immediately to $0.6 \mathrm{ml}$ ice-cold $25 \%$ polyethylene glycol (PEG; mol. wt. 6000; Sigma Ltd, Poole, UK). Samples were stored at

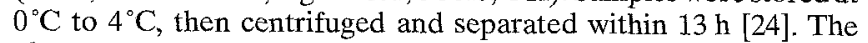
plasma was stored at $-20^{\circ} \mathrm{C}$ until assay by double-antibody radioimmunoassay (Guildhay Antisera Ltd, Guildford, UK) modified from Morgan and Lazarow [24]. Interassay CVs at 12.2 and $47.2 \mathrm{mU} / \mathrm{l}$ were 5.5 and $8.6 \%$, respectively.

For ketone measurement $1.0 \mathrm{ml}$ whole blood was added immediately to $3.0 \mathrm{ml}$ of ice-cold $10 \%$ perchloric acid (PCA) and mixed. Samples were stored at $0-4^{\circ} \mathrm{C}$ for up to $13 \mathrm{~h}$, then spun and the pre- 
Table 1. Plasma growth hormone (GH) concentrations (mean \pm SEM) of all subjects during three study nights

\begin{tabular}{|c|c|c|c|c|c|c|}
\hline \multirow[t]{3}{*}{ Study night } & \multicolumn{6}{|c|}{ Plasma growth hormone concentration } \\
\hline & \multirow{2}{*}{$\begin{array}{l}\text { Before } \\
\text { somatostatin } \\
(\text { mean } \pm \text { SEM) }\end{array}$} & \multirow{2}{*}{$\begin{array}{l}1 \text { h after somato- } \\
\text { statin infusion } \\
\text { (mean } \pm S E M \text { ) }\end{array}$} & \multicolumn{4}{|l|}{$20.00-08.00$ hours } \\
\hline & & & $\begin{array}{l}\text { overnight mean level } \\
( \pm \text { SEM })\end{array}$ & $\begin{array}{l}\text { peak l } \\
\text { (mean }\end{array}$ & oulsatile & tration \\
\hline Continuous GH & $7.1 \pm 3.1$ & $1.4 \pm 0.4$ & $9.7 \pm 0.4$ & - & - & - \\
\hline Pulse GH & $1.2 \pm 0.3$ & $0.6 \pm 0.03$ & $9.8 \pm 1.5$ & $\begin{array}{l}29.2 \\
\pm 2.7\end{array}$ & $\begin{array}{l}31.6 \\
\pm 2.6\end{array}$ & $\begin{array}{l}33.7 \\
\pm 3.2\end{array}$ \\
\hline
\end{tabular}

cipitate discarded. The supernatant was neutralised using $2 \%$ and $20 \%$ potassium hydroxide and $10 \% \mathrm{PCA}$. Assay of all three metabolites were standard enzymatic techniques [26]. Inter- and intraassay CVs for the B-hydroxybutyrate assay were 8.3 and $2.2 \%$, and for the acetoacetate assay, $5.3 \%$ and $2.2 \%$, respectively. Lactate inter- and intra-assay CVs were $5.1 \%$ and $1.0 \%$, respectively. Samples for NEFA were kept in EDTA at room temperature until the study was complete then spun, separated and stored at $-20^{\circ} \mathrm{C}$ until analysis. Assay was by enzymatic colorimetric kit (Wako Chemicals \& Alpha Laboratories, Eastleigh, Hants, UK). The inter-assay CV at $0.39 \mathrm{mmol} / \mathrm{h}$ was $4.4 \%$ and intra-assay $\mathrm{CVs}$ at $0.33,0.62,0.99 \mathrm{mmol} / 1$ were $2.7 \%, 1.1 \%$ and $1.1 \%$, respectively.

\section{Statistical analysis}

Results are given as mean \pm SEM unless otherwise stated. Blood glucose and insulin infusion data were normally distributed. Log-transformation normalised the ketone, lipid and plasma free insulin data and therefore parametric statistical techniques have been used on these log-transformed data. Student's paired $t$-test was used for comparisons of mean data between profiles and at individual time periods. Analysis of variance (two-way ANOVA) was used to examine changes with time and confirm differences between study nights. An $F$ test of variance was used to compare differences between the insulin infusion rates on the three study nights.

Cross-correlation [27] was used to examine the phase relationships between oscillations in the GH data and insulin requirements. This involves time series data (GH pulses) being correlated with insulin infusion rates which are then lagged with respect to the GH pulses by intervals of 1 min and correlated again. Data in phase have a positive $r$ value at zero lag. If there are regular cycles the serial values of $r$ will fall until they reach a madir when the data are $180^{\circ}$ out of phase. The first positive peak represents the period of any regularly recurring cycle.

\section{Results}

\section{Growth hormone}

Endogenous plasma $\mathrm{GH}$ levels were effectively suppressed after $1 \mathrm{~h}$ somatostatin infusion on all study nights before administration of $\mathrm{GH} / \mathrm{buffer}$. $\mathrm{GH}$ (mean $\pm \mathrm{SEM}$ ) $0.08 \pm 0.2 \mathrm{mU} / 1,1.4 \pm 0.04 \mathrm{mU} / \mathrm{h}, 1.1 \pm 0.3 \mathrm{mU} / \mathrm{l}$ on nights with pulsatile $\mathrm{GH}$ infusion, continuous $\mathrm{GH}$ infusion and control respectively (Table 1 ). The GH dose administered during the continuous infusion ranged between $78-$ $121 \mathrm{mU} / \mathrm{h}$ and between $312-484 \mathrm{mU} / \mathrm{pulse}$ on the night of pulsed GH administration. Mean GH (20.00-08.00 hours) levels achieved were similar at $9.7 \pm 0.4$ and $9.8 \pm 1.5 \mathrm{mU} /$, respectively. Mean GH levels on the control night remained suppressed at $1.1 \pm 0.1 \mathrm{mU} / 1$.
Following pulsatile $\mathrm{GH}$ administration, plasma levels rose by $30 \mathrm{~min}$ and reached peak plasma levels by $60 \mathrm{~min}$. After the cessation of the GH infusion, the pulse was sustained for $30 \mathrm{~min}$ (time taken to reach half-peak levels) and had reached suppression levels by $60 \mathrm{~min}$. Pulse characteristics achieved in all study patients $(n=5)$ were similar and there were no differences between the first, second and third pulses (mean peak GH levels, $29.2 \pm 2.7$ vs $31.6 \pm 2.6$ vs $33.7 \pm 3.2 \mathrm{mU} / 1$ respectively; $p=\mathrm{NS}$ ) (Fig. $1 \mathrm{a}$ ).

Administration of continuous $\mathrm{GH}$ infusion resulted in a rise in plasma $\mathrm{GH}$ levels by 30 min and levels reached a plateau level by $120 \mathrm{~min}$. Thereafter, steady GH levels were observed (8.6-10.8 mU/l) (Fig. 1 b).

\section{The glucose clamp}

Euglycaemia $(<6 \mathrm{mmol} / 1)$ was achieved by 22.00 hours on all study nights. The lowest blood glucose levels measured at any time were no different on any of the three occasions and no subject became hypoglycaemic. Euglycaemic mean clamp glucose levels achieved on the study nights (01.00-08.00 hours) were comparable: $5.5 \pm 0.5 \mathrm{mmol} / 1$ during continuous $\mathrm{GH}$ infusion, $5.9 \pm 0.5 \mathrm{mmol} / /$ during the pulsatile $\mathrm{GH}$ infusion and $5.3 \pm 0.4 \mathrm{mmol} / \mathrm{l}$ during the control night (Fig. 2). However, during the night with a pulsatile $\mathrm{GH}$ infusion, blood glucose levels were more difficult to control despite increases in insulin infusion rates and were significantly higher between $05.00-08.00$ hours. This was reflected in a significantly higher fasting glucose level during the pulsatile GH infusion night $(6.5 \pm 0.4 \mathrm{mmol} / \mathrm{l})$ when compared with the control night $(5.4 \pm 0.5 \mathrm{mmol} / 1, p<0.001)$.

\section{Insulin infusion requirements and plasma insulin levels}

Mean insulin requirements between $01.00-08.00$ hours were greater during the pulsatile $\mathrm{GH}$ infusion $\left(0.17 \pm 0.03 \mathrm{mU} \cdot \mathrm{kg}^{-1} \cdot \mathrm{min}^{-1}\right)$ when compared with the control night $\left.\left(0.09 \pm 0.01 \mathrm{mU} \cdot \mathrm{kg}^{-1} \cdot \mathrm{min}^{-1} ; p<0.05\right)\right)$. Insulin requirements during the night when continuous $\mathrm{GH}$ was infused $\left(0.10 \pm 0.01 \mathrm{mU} \cdot \mathrm{kg}^{-1} \cdot \mathrm{min}^{-1}\right)$ were not significantly different from the control night. $F$ test on the variance showed an increased variability of the insulin infused on the night when pulsed $\mathrm{GH}$ was given compared with either nights of continuous $\mathrm{GH}$ administration or control $(p<0.01)$.

The change in insulin requirement during the night when pulsatile GH was administered represents a mean 

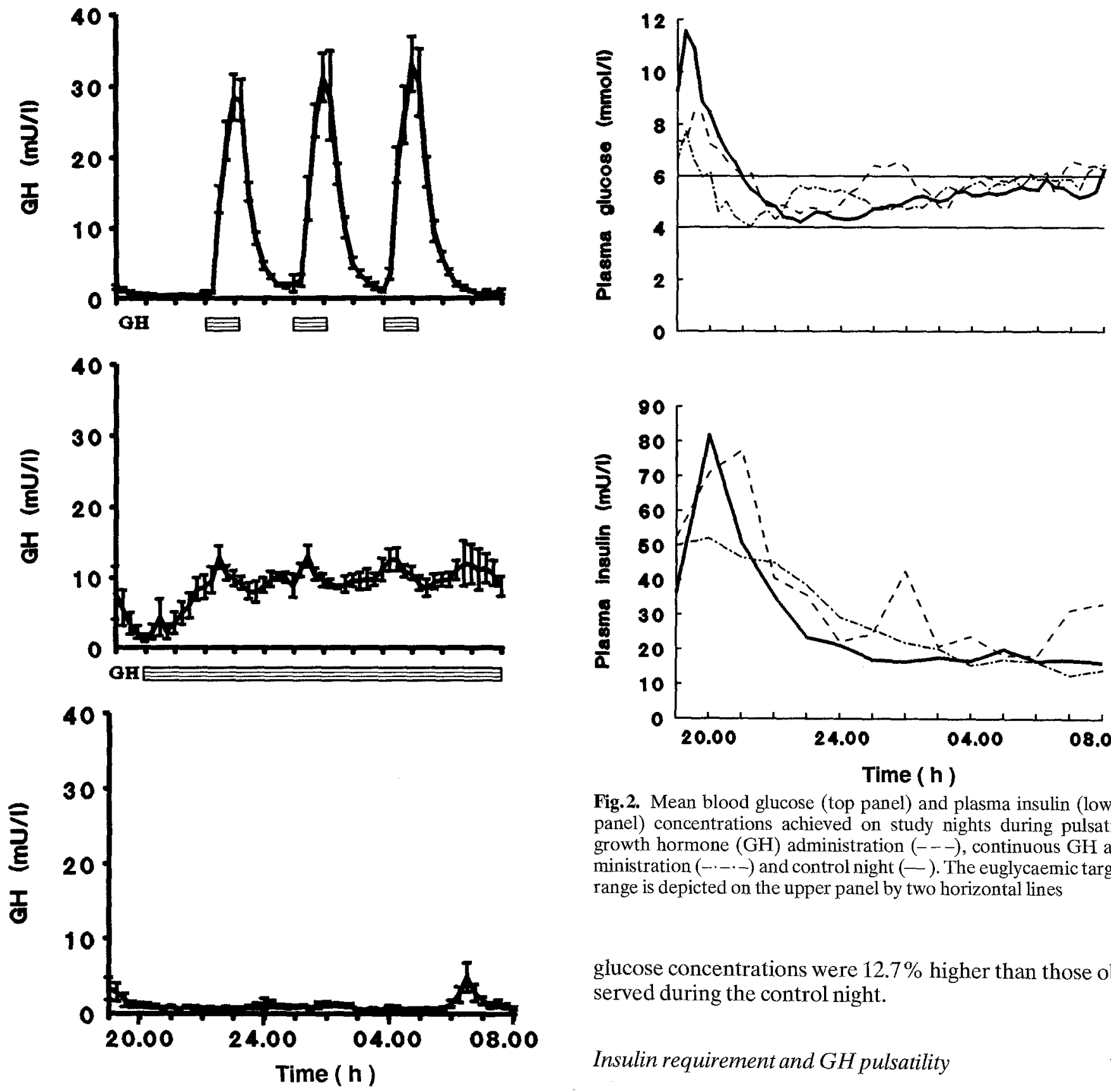

Fig. 1. Plasma growth hormone $(\mathrm{GH})$ profiles. Mean \pm SEM levels achicved on study nights during pulsatile $\mathrm{GH}$ administration (top panel), continuous $\mathrm{GH}$ administration (middle panel) and control night (lower panel)

increase of insulin infusion requirement of $88.8 \%$ during the night. Plasma free insulin levels (01.00-08.00 hours) were correspondingly higher on the night with a pulsatile GH infusion: $26.53 \pm 3.01 \mathrm{mU} / \mathrm{l}$ vs control $17.16 \pm 0.42 \mathrm{mU} / 1$ ( $p=0.01$ ) (Fig. 2). Mean plasma free insulin was also significantly higher during the night of pulsatile $\mathrm{GH}$ administration $(26.5 \pm 3.01 \mathrm{mU} / \mathrm{l})$ than during continuous administration $(17.16 \pm 0.42 \mathrm{mU} / \mathrm{l}$; $p=0.01$ ).

During the night when pulsatile GH was administered, despite an $88 \%$ increase in insulin infused, mean blood

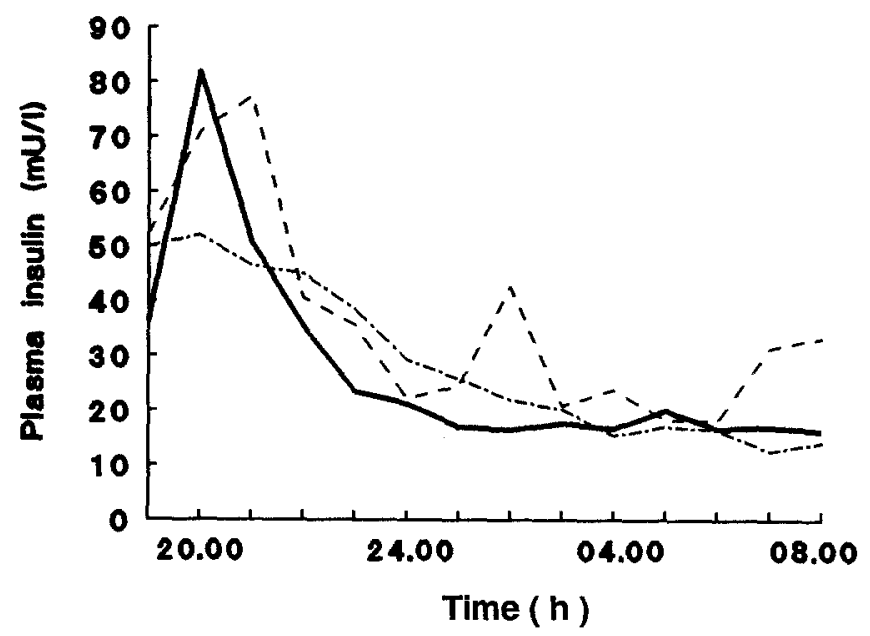

Fig. 2. Mean blood glucose (top panel) and plasma insulin (lower panel) concentrations achieved on study nights during pulsatile growth hormone (GH) administration $(---)$, continuous $\mathrm{GH}$ administration (-- - $)$ ) and control night $(-)$. The euglycaemic target range is depicted on the upper panel by two horizontal lines

glucose concentrations were $12.7 \%$ higher than those observed during the control night.

\section{Insulin requirement and $G H$ pulsatility}

Figure 3 shows the relationship between insulin infusion rates and GH pulses during the night of pulsatile $\mathrm{GH}$ administration. There appeared to be a rise in insulin requirement approximately $2 \mathrm{~h}$ following a GH pulse which was maximal at $3 \mathrm{~h}$ and had fallen again by $4 \mathrm{~h}$. Crosscorrelation was used to elaborate this relationship further and it showed that changes in insulin infusion rates and GH pulses showed a maximal significant positive association $(r=0.21, p<0.001)$ with a lag time $135 \mathrm{~min}$ (Fig. 4), indicating that an increase in insulin requirement lagged 135 min after a GH pulse.

\section{Metabolic effects}

The pattern of B-hydroxybutyrate, acetoacetate and NEFA concentrations during the study nights are shown in Figure 5. Plasma ketone levels showed an initial fall 


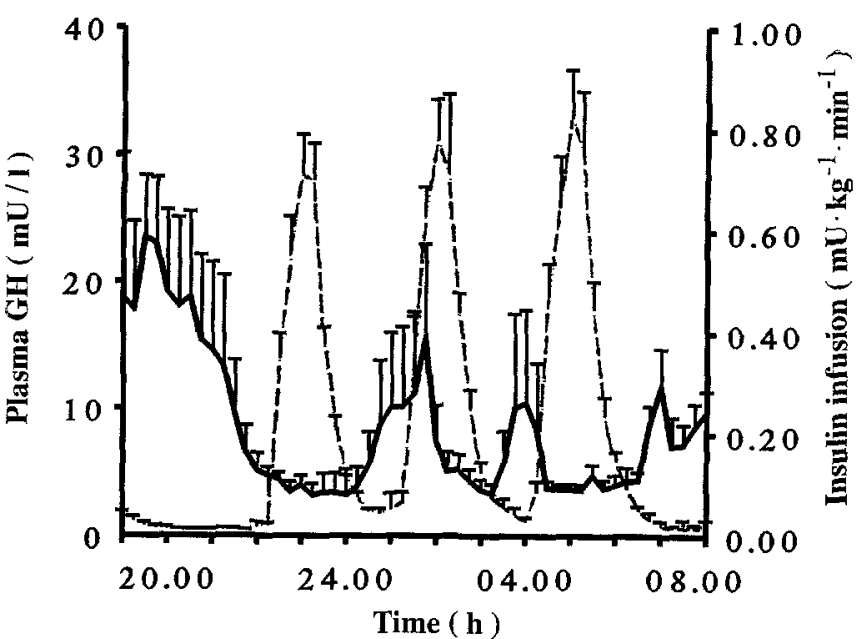

Fig.3. The overnight oscillations of insulin infusion requirements $(-)$ (mean \pm SEM) and the plasma concentration of growth hormone $(---)$ (mean $\pm S E M)$ during the night of pulsatile growth hormone administration

from 19.00 hours levels, and then rose steadily from 21.00 hours (during the night of continuous GH infusion) and 23.00 hours (during the night of pulsatile GH infusion) until peak levels were reached between 01.00 02.00 hours. No change was observed on the control night. The levels of ketones then remained at this high level until 08.00 hours. The rise in B-hydroxybutyrate was more pronounced during the nights with continuous $\mathrm{GH}$ administration.

Mean overnight (01.00-08.00 hours) B-hydroxybutyrate levels were significantly increased on both GH infusion nights: $0.21 \pm 0.01 \mathrm{mmol} / 1$ (mean $\pm \mathrm{SEM}$ ), $0.29 \pm 0.01 \mathrm{mmol} / 1,0.08 \pm 0.01 \mathrm{mmol} / 1(p<0.001)$ during the night with pulsatile $\mathrm{GH}$, continuous $\mathrm{GH}$ and control, respectively. Plasma acetoacetate concentrations followed a similar pattern: $0.156 \pm 0.006 \mathrm{mmol} / \mathrm{l}$, $0.183 \pm 0.006 \mathrm{mmol} / 1, \quad 0.092 \pm 0.004 \mathrm{mmol} / \mathrm{l} \quad(p<0.001)$ during the nights with pulsatile $\mathrm{GH}$, continuous $\mathrm{GH}$ and control, respectively. These changes were confirmed by ANOVA using log transformed data, and the greatest changes were detected on nights where GH was administered continuously but levels on both nights where $\mathrm{GH}$ was administered were greater than control nights.

Lactate levels fell initially from 20.00 hours and did not vary significantly over time during the later period (01.0008.00 hours, $\mathrm{F} 1.13, p=\mathrm{NS}$ ) on any of the treatment nights. However, there was a small but significant difference in the changes of levels on the night of pulsatile GH (F 5.9, $p<0.05$ ) and continuous GH (F 3.87, $p<0.05$ ) administration when compared with the control night (ANOVA). Mean plasma lactate levels were slightly raised following pulsatile $\mathrm{GH}$ administration: mean level (01.00-08.00 hours) on pulsatile GH infusion night $0.94 \pm 0.04 \mathrm{mmol} / 1$ vs control $0.80 \pm 0.02(p=0.045)$.

Overnight (01:00-08.00 hours) mean levels of NEFA were significantly increased following the night of continuous GH infusion $(1.09 \pm 0.07 \mathrm{mmol} / 1$ vs control $0.61 \pm 0.05 \mathrm{mmol} / 1(p<0.001)$, and also during the night of pulsatile GH administration $(0.94 \pm 0.04 \mathrm{mmol} / 1$ vs con- trol $(p<0.05)$. Fasting levels however were not significantly different: $1.04 \pm 0.16 \mathrm{mmol} / \mathrm{l}, 0.83 \pm 0.13 \mathrm{mmol} / \mathrm{l}$, $0.64 \pm 0.13 \mathrm{mmol} / \mathrm{l}$ on the nights of continuous and pulsatile $\mathrm{GH}$ administration and control nights, respectively. ANOVA confirmed that NEFA levels did not change with time between $01.00-08.00$ hours (F 0.50 ) but there was a significant difference in mean plasma levels which were higher following continuous $\mathrm{GH}$ administration when compared with either control ( $\mathrm{F} 27.08, p<0.005)$ or pulsatile $\mathrm{GH}$ infusion (F 19.15, $p<0.005)$.

\section{Discussion}

The increased GH concentrations in Type 1 diabetes have been causally related to adverse metabolic effects on glucose control [6], insulin sensitivity, ketogenesis and lipid metabolism $[28,29]$. GH has both insulin-like and anti-insulin-like properties [30]. Early insulin-like and delayed insulin-antagonistic effects of human $\mathrm{GH}$ on glucose metabolism have been observed during infusion of human GH in normal subjects [31]. The insulin-like effects occur within $1 \mathrm{~h}$ of the initiation of human GH infusion and are attributed to a decrease in hepatic glucose production and an increase in peripheral glucose utilization. These effects are transient and 4-6 h later, the insulin antagonistic effects of GH predominate. In normal man exogenous GH administered to physiological levels causes insulin resistance, impairing the ability of insulin to suppress hepatic glucose utilization [32]. This hyperglycaemic effect is characterised by decreased insulin receptor binding affinity, as well as a probable post-receptor defect [32,33]. In normal subjects these effects can be modified by a compensatory increase in insulin secretion. In subjects with Type 1 diabetes similar effects can be demonstrated by an increased insulin requirement during clamp studies.

In our studies an increase in insulin requirements was observed following pulsatile GH administration, but not when an identical amount of GH was administered as a

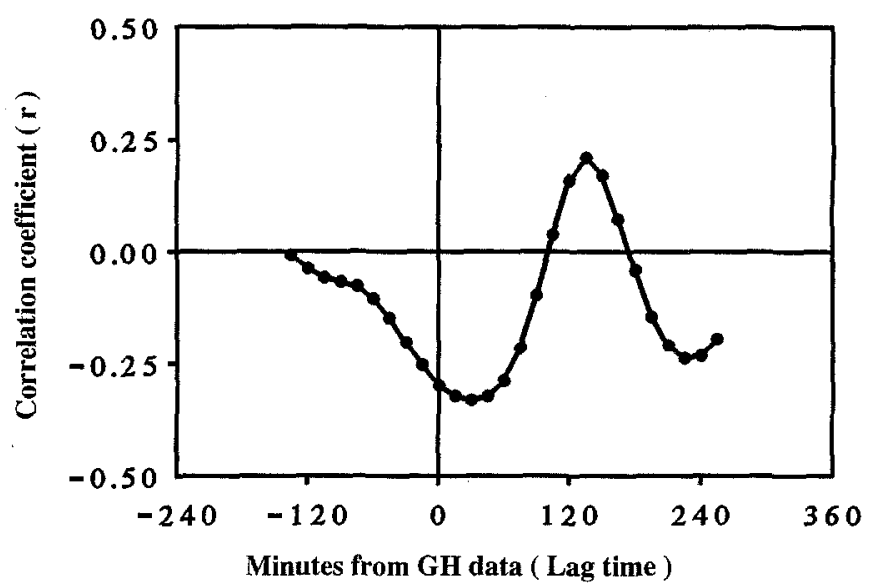

Fig.4. Cross-correlation between growth hormone $(\mathrm{GH})$ concentration: insulin infusion rate shown here as a correlogram. A maximal significant positive association is seen at $135 \mathrm{~min}$ lag time $(r=0.21, p<0.001)$, indicating that on average maximal insulin infusion rates are required $135 \mathrm{~min}$ after a $\mathrm{GH}$ pulse 

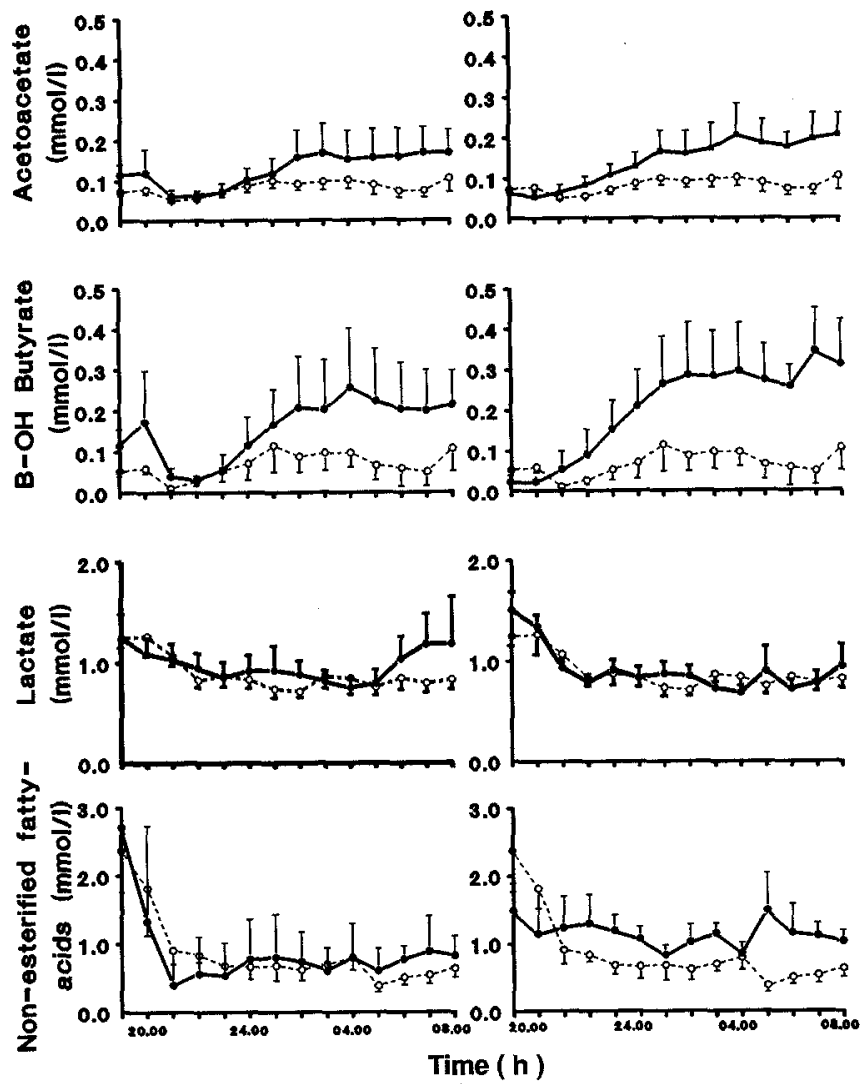

Fig.5. Results of overnight metabolic data (mean \pm SEM). Left panels show results from nights when growth hormone (GH) was given as a pulsatile infusion and the right panels show results from continuous GH administration. Solid symbols are data from night of GH infusion, open symbols from control night. Ordinate show overnight plasma concentrations of acetoacetate, B-hydroxybutyrate, lactate and non-esterified fatty acids

continuous infusion. These observations were confirmed by the finding of higher insulin concentrations on nights when pulsatile GH was administered than on control nights and nights of continuous $\mathrm{GH}$ administration despite similar euglycaemic conditions. Perriello et al. [20] in a recent study of subjects with Type 1 diabetes observed a similar difference when they compared the effects of basal vs basal and pulsatile GH administration. We noted a clear temporal relationship between the GH pulses and the change in insulin requirement which was confirmed by cross-correlation analysis. A change in insulin requirements was observed $135 \mathrm{~min}$ after a GH pulse which lasted $240 \mathrm{~min}$. Moller et al. [34] in a study of the effects of GH pulse administration on forearm substrate fluxes in humans showed a change in glucose uptake which was maximal at $120 \mathrm{~min}$ and sustained for $240 \mathrm{~min}$. Levels of $\mathrm{GH}$ achieved in those studies $(21 \mu \mathrm{g} / \mathrm{l}=42 \mathrm{mU} / \mathrm{l})$ were higher than those achieved by us $(31.5 \mathrm{mU} / \mathrm{l})$ but the changes in insulin sensitivity were very similar. These changes in insulin sensitivity cannot be explained by changes in plasma IGF-I levels, as the lag period for IGF-I production is $8 \mathrm{~h}$ and no differences in mean or 08.00 hours levels of IGF-I measured by radioimmunosassay were observed when the three study nights were compared (data not shown).
These observations may have implications for our understanding of the dawn phenomenon. Studies indicate that the dawn phenomenon is due to a decrease in insulin sensitivity induced by nocturnal surges of $\mathrm{GH}$ secretion [9-12]. We and others have shown that the dawn increase in insulin requirements can be correlated with parameters of GH pulse amplitude (mean GH, sum of peak amplitude) and suppression of nocturnal GH release appears to reduce the extent of the dawn increase in insulin requirement $[12,13]$. Perriello et al. [20] in their studies compared insulin requirements between $24.00-02.00$ hours and 06.00-08.00 hours and noted an increase in insulin requirements on nights where basal GH administration was supplemented by pulsatile GH delivery compared to nights where only basal GH levels were replaced. In our studies such comparisons were not possible because of the oscillations in insulin requirements following $\mathrm{GH}$ pulses.

The plasma profiles which we achieved when GH was administered as pulses were comparable to those observed in adolescents with Type 1 diabetes [5] with first pulse peak occurring at 23.00 hours. The pulse frequency we chose was $180 \mathrm{~min}$; this being the dominant pulse periodicity in normal [14] and diabetic subjects determined by Fourier analysis during puberty [5]. However, there is evidence that the number of GH pulses overnight may be greater in young adults [16] and adolescents with Type 1 diabetes [17]. An increase in pulse frequency might lead to a gradual recruitment of insulin resistance throughout the night. Further, in a recent study, Fowelin et al. [35] showed that the duration of the insulin resistance following a $\mathrm{GH}$ pulse was dependent on the peak GH levels. Whereas peak $\mathrm{GH}$ levels of $30 \mathrm{mU} / 1$ produced changes in insulin requirements similar to those observed in our studies, levels of $50 \mathrm{mU} / 1$ produced a sustained change in insulin sensitivity lasting $6-7 \mathrm{~h}$. Levels far in excess of $50 \mathrm{mU} / \mathrm{l}$ are often observed in adolescents with Type 1 diabetes. Variations in the frequency and amplitude of GH pulses may explain the sustained changes in insulin sensitivity and the variability characteristic of the dawn phenomenon in Type 1 diabetes.

Whereas changes in insulin requirements were solely related to pulsatile $\mathrm{GH}$ administration, the effects on $\mathrm{B}$ hydroxybutyrate and acetoacetate were evident on both $\mathrm{GH}$ infusion nights and were more marked on the nights when continuous GH was administered. The lipolytic and ketogenic effects of $\mathrm{GH}$ have been demonstrated in normal subjects made insulin-deficient by somatostatin [36] and in insulin-deficient diabetic patients [28]. Hyperketonaemia may result from increased lipolysis with an increased NEFA supply for ketogenesis or from a primary action of $\mathrm{GH}$ on hepatic ketone body production or peripheral utilization. If sufficient insulin is available, much of the ketogenic activity of GH is suppressed [28]. However, although a variable insulin clamp allowed optimum delivery of insulin to maintain euglycaemia throughout the study nights, ketone levels remained elevated.

Moller et al. [34], in their studies of pulsatile GH administration, noted an increase in B-hydroxybutyrate maximal at $2 \mathrm{~h}$ which was reversed by $4 \mathrm{~h}$. However, we noted no reversal in B-hydroxybutyrate even on nights where pulsatile GH was administered but levels were 
measured hourly and fluctuations in levels may not have been adequately documented. The greater levels during continuous $\mathrm{GH}$ infusion nights might solely reflect the higher insulin levels on pulsatile GH infusion nights. Jorgensen et al. observed no differences between B-hydroxybutyrate after pulsatile or continuous delivery of $\mathrm{GH}$ to GH deficient subjects but insulin and glucagon levels were not controlled in those studies [37].

$\mathrm{GH}$ stimulates lipolysis, providing glycerol as a substrate for gluconeogenesis and NEFA which impair tissue glucose oxidation [38]. NEFA were elevated on both GH infusion nights but the changes were more marked after continuous GH administration. In normal subjects NEFA rise during the night [39] but following $\mathrm{GH}$ administration the acute lipolytic actions of $\mathrm{GH}$ are limited by a compensatory rise in insulin secretion and it is only during chronic ( $24 \mathrm{~h}$ ) GH exposure that lipolytic effects are seen [36]. In Type 1 diabetes fasting NEFA levels are increased. The lower levels which we observed following nights where pulsatile $\mathrm{GH}$ was infused when compared with continuous $\mathrm{GH}$ administration might reflect increased insulin levels on these nights, as lipolysis is sensitive to small changes in peripheral insulin concentrations [40]. The high basal concentrations of GH which are observed in Type 1 diabetes in many ways mimic those observed during fasting which is also associated with a sustained rise in NEFA [42]. Basal concentrations of GH may therefore be an important metabolic 'signal' for both lipolysis and ketogenesis.

From our studies we would conclude that the elevated $\mathrm{GH}$ pulse amplitude rather than the elevated baseline $\mathrm{GH}$ concentrations leads to changes in insulin requirements overnight. However, changes in baseline concentrations may be the more important 'signal' for the stimulation of ketogenesis and lipolysis in these subjects. The differential metabolic effects of changes in both pulse amplitude and baseline $\mathrm{GH}$ concentrations need to be considered when therapeutic suppression of GH concentrations is attempted.

Acknowledgements. BRP was supported by a grant from Kabi Pharmacia, Stockholm, Sweden. We would like to thank Serono for providing the Stilamin and Kabi Pharmacia for providing the Genotropin used in these studies. Assistance from Ms. J.Gilbert, Ms. D. Harris, Ms. S. Strang and the Pharmacy Department at John Radcliffe Hospital is gratefully acknowledged.

\section{References}

1. Johansen K, Hansen AP (1971) Diurnal serum growth hormone levels in poorly and well-controlled juvenile diabetics. Diabetes 20: $239-245$

2. Hansen AP (1970) Normalization of growth hormone hyperresponse to exercise in juvenile diabetics after normalization of blood sugar. J Clin Invest 50: 1806-1811

3. Merimee TJ, Fitzgerald CR, Gold LA, McCourt JP (1979) Characteristics of growth hormone secretion in clinically stable diabetes. Diabetes 28: 308-312

4. Hayford JT, Danney MM, Hendrix JA, Thompson RG (1980) Integrated concentration of growth hormone in juvenile-onset diabetes. Diabetes 29: 391-398
5. Edge JA, Dunger DB, Matthews DR, Gilbert JP, Smith CP (1990) Increased overnight growth hormone concentrations in diabetic compared with normal adolescents. J Clin Endocrinol Metab 71: 1356-1362

6. Press M, Tamborlane WV, Sherwin RS (1984) Importance of raised growth hormone levels in mediating the metabolic derangements of diabetes. N Engl J Med 310: 810-815

7. Gerich JE (1984) Role of growth hormone in diabetes mellitus. N Engl J Med 310:848-850

8. Gerich JE (1986) Rationale for inhibition of growth hormone secretion in the management of the diabetic patient. Scand $\mathrm{J}$ Gastroenterol 21 [Suppl 119]: 154-157

9. Campbell PJ, Bolli GB, Cryer PE, Gerich JE (1985) Sequence of events during development of the dawn phenomenon in insulindependent diabetes mellitus. Metabolism 34: 1100-1104

10. Davidson MB, Harris MD, Ziel FH, Rosenberg CS (1988) Suppression of sleep-induced growth hormone secretion by anticholinergic agents abolishes dawn phenomenon. Diabetes 37: 166171

11. Perriello G, De Feo P, Bolli GB (1988) The dawn phenomenon: nocturnal blood glucose homeostasis in insulin-dependent diabetes mellitus. Diab Med 5: 13-21

12. Atiea JA, Creagh F, Page M, Owens DR, Scanlon MF, Peters JR (1989) Early morning hyperglycaemia in insulin-dependent diabetes: acute and sustained effects of cholinergic blockade. J Clin Endocrinol Metab 69: 390-395

13. Edge JA, Matthews DR, Dunger DB (1990) The dawn phenomenon is related to overnight growth hormone release in adolescent diabetics. Clin Endocrinol 33: 729-737

14. Hindmarsh PC, Matthews DR, Brook CGD (1988) Growth hormone secretion in children determined by time series analysis. Clin Endocrinol 29: 35-44

15. Horner JM, Kemp SF, Hintz RL (1981) Growth hormone and somatomedin in insulin-dependent diabetes mellitus. J Clin Endocrinol Metab 53: 1148-1153

16. Asplin CM, Faria ACS, Carlsen EC et al. (1989) Alterations in the pulsatile mode of growth hormone release in men and women with insulin-dependent diabetes mellitus. J Clin Endocrinol Metab 69:239-245

17. Pal BR, Matthews DR, Mullis PE, Edge JA, Hindmarsh PC, Dunger DB (1991) The half-life, volume of distribution and secretory rates of growth hormone in adolescents with IDDM. $\mathbf{J}$ Endocrinol 129 [Suppl]: 92 (Abstract)

18. Maiter D, Underwood LE, Maes M, Davenport ML, Ketelslegers JM (1988) Different effects of intermittent and continuous growth hormone $(\mathrm{GH})$ administration on serum somatomedin C/insulin-like growth factor I and liver GH receptors in hypophysectomised rats. Endocrinology 123: 1053-1059

19. Sirek A, Sirek OV (1990) The metabolic effects of plasma growth hormone surges. Diab Nutr Metab 3: 157-169

20. Perriello G, De Feo P, Torlone E et al. (1990) Nocturnal spikes of growth hormone secretion cause the dawn phenomenon in Type 1 (insulin-dependent) diabetes mellitus by decreasing hepatic (and extra-hepatic) sensitivity to insulin in the absence of insulin waning. Diabetologia 33: 52-59

21. Hindmarsh PC, Matthews DR, Brain C, Pringle PJ, Brook CGD (1990) The application of deconvolution analysis to elucidate the pulsatile nature of growth hormone secretion using a variable half-life of growth hormone. Clin Endocrinol 32: 739-747

22. Matthews DR, Edge JR, Dunger DB (1990) An unbiased glucose clamp method using a variable insulin infusion: its application in diabetic adolescents. Diab Med 7: 246-251

23. McGuire EAH, Helderman JH, Tobin JD, Andres R, Berman M (1976) Effects of arterial versus venous sampling on analysis of glucose kinetics in man. J Appl Physiol 41:565-573

24. Collins ACG, Pickup JC (1985) Sample preparation and radioimmunoassay for circulating free and antibody-bound insulin concentrations in insulin-treated diabetics: a re-evaluation of methods. Diab Med 2: 456-460

25. Morgan CR, Lazarow A (1963) Immunoassay of insulin: two antibody system. Diabetes 12: 115-126 
26. Williamson DH, Mellanby J (1974) D-( - )-3-hydroxybutyrate. In: Bergmayer HU (ed) Methods of enzymatic analysis, Vol 4. Academic Press, New York pp 1836-1839

27. Chatfield C (1975) The analysis of time series: theory and practice. Chapman and Hall, London

28. Gerich JE, Lorenzi M, Bier DM et al. (1976) Effects of physiological levels of glucagon and growth hormone on human carbohydrate and lipid metabolism. Studies involving administration of exogenous hormone during suppression of endogenous hormone secretion with somatostatin. J Clin Invest 57: $875-884$

29. Seng G, Galgoti C, Louisy P, Toussain P, Drouin P, Derby G (1989) Metabolic effects of a single administration of growth hormone on lipid and carbohydrate metabolism in normal-weight and obese subjects. Am J Clin Nutr 50: 1348-1354

30. Davidson MB (1987) Effect of growth hormone on carbohydrate and lipid metabolism. Endocr Rev 8:115-131

31. MacGorman LR, Rizza RA, Gerich JE (1981) Physiological concentrations of growth hormone exert insulin-like and insulin antagonistic effects on both hepatic and extrahepatic tissues in man. J Clin Endocrinol Metab 53: 556-559

32. Rizza RA, Mandarino LJ, Gerich JE (1982) Effects of growth hormone on insulin action in man. Diabetes 31: 663-669

33. Bratusch-Marrain PR, Smith D, DeFronzo RA (1982) The effect of growth hormone on glucose metabolism and insulin secretion in man. J Clin Endocrinol Metab 55: 973-982

34. Moller N, Jorgensen JOL, Schmitz O et al. (1990) Effects of a growth hormone pulse on total and forearm substrate fluxes in humans. Am J Physiol 258: E86-E91

35. Fowelin J, Attval S, Van Schenck H, Smith U, Lager I (1991) Characterization of the insulin-antagonistic effect of growth hormone in man. Diabetologia 34: 500-506
36. Metcalfe P, Johnston DG, Nosadini R, Ørksov H, Alberti KGMM (1981) Metabolic effects of acute and prolonged growth hormone excess in normal and insulin-deficient man. Diabetologia 20: 123-128

37. Jorgensen JOL, Moller N, Lauritzen T, Christiansen JS (1990) Pulsatile versus continuous intravenous administration of growth hormone in $\mathrm{GH}$ deficient patients. Effects of circulating insulin-like growth factor I and metabolic indices. J Clin Endocrinol Metab 70: 1616-1623

38. Johnston DG, Davies RR, Prescott RWG (1985) Regulation of growth hormone secretion in man: a review. JR Soc Med 78:319327

39. Wildenhoff KE (1972) Diurnal variations in the concentrations of blood acetoacetate, 3-hydroxybutyrate and glucose on normal persons. Acta Med Scand 191:303-306

40. Nestel PH, White HM (1967) Relationship between FFA flux and TFGA influx in plasma before and during the infusions of insulin. Metabolism 16: 1123-1132

41. Ho KY, Veldhuis JD, Johnson ML et al. (1988) Fasting enhances growth hormone secretion and amplifies the complex rhythms of growth hormone secretion in man. J Clin Invest 81: 968-975

Received: 25 October 1991

and in revised form: 23 January 1992

Dr. D.B. Dunger

Department of Paediatrics

John Radcliffe Hospital

Headington

Oxford OX3 9DU

UK 